Article

\title{
Introducing Sustainability in a Robotic Engineering Degree: A Case Study
}

\author{
Francisco A. Pujol ${ }^{1, *(1)}$ and David Tomás ${ }^{2}$ (1) \\ 1 Department of Computer Technology, University of Alicante, 03690 San Vicente del Raspeig-Alicante, Spain \\ 2 Department of Software and Computing Systems, University of Alicante, 03690 San Vicente del \\ Raspeig-Alicante, Spain; dtomas@dlsi.ua.es \\ * Correspondence: fpujol@ua.es
}

Received: 15 June 2020; Accepted: 7 July 2020 ; Published: 10 July 2020

\begin{abstract}
This paper describes a group activity concerning the topic of climate change, designed to introduce the concepts of sustainable development into a Robotic Engineering degree. The purpose of this activity was to make students reflect about the impact of their work on the planet as future engineers by asking them to design an environmentally friendly robot that also integrated social and economic aspects, covering the three dimensions of sustainability in this way. Students were surveyed in order to study different aspects of their commitment, attitudes, practices, and motivation towards sustainability. In addition to the overall analysis of the survey, three specific studies were carried out with the aim of comparing the responses of different population groups: (i) Students who completed the proposed assignment and students who did not, (ii) female and male students, and (iii) roles played in the assignment. The results of the analysis revealed the high commitment of the students with respect to sustainability, but also a lack of active participation and awareness of their impact as future engineers. The activity was not only a way to introduce sustainability concepts, but in many cases, it also became a motivation for the participants, especially for the female students.
\end{abstract}

Keywords: education for sustainable development; engineering education; robotic engineering; gender bias

\section{Introduction}

Engineers are critical for achieving many of the 17 Sustainable Development Goals (SDGs) defined in the 2030 Agenda for Sustainable Development, adopted by all United Nations Member States in 2015 (https: / / www.un.org/sustainabledevelopment/, accessed on 10 July 2020). Engineering projects are essential in implementing technologies and systems related to inclusive technologies for women (Goal 5), clean water and sanitation (Goal 6), availability of sustainable energy sources (Goal 7), natural disaster resilience (Goal 9), sustainable cities (Goal 11), and climate change (Goal 13). Engineers are also crucial for sustainable economic development (Goal 8), since they support the growth of required infrastructures, such as roads, waste management, and digital networks in both developed and developing countries. For these reasons, engineering education should focus its efforts on training engineers to be active agents of sustainability in the world [1].

Education for sustainable development (ESD) is one of the specific targets of SDG 4 (quality education), which is recognized as a critical enabler for sustainable development. ESD is not only important in SDG 4, but is also essential for the fulfillment of all other SDGs. ESD also helps to advance the change in teaching and learning processes, introducing approaches that encourage students to think critically, ask questions, analyze, and make decisions. ESD helps individuals to better understand the impacts, both environmental and social, of their lifestyle choices [2]. 
According to the World Federation of Engineering Organizations (http:/ / www.wfeo.org), ESD encourages engineers to play "an important role in planning and building projects that preserve natural resources, are cost-efficient, and support human and natural environments". This includes the teaching of technical, social, and economic aspects of development [3]. These competencies address SDGs in a way that allows future engineers to predict possible harm to the environment from newly created production technologies beforehand by projecting measures of harm prevention [4].

To have a positive impact on sustainable development, engineering education has to include projects that help students to develop personal, teamwork, and problem-solving skills, providing opportunities for meaningful experiences to reflect on how the abstract concepts that engineers learn in courses apply to the real world [1]. This paper describes an ESD experience carried out to introduce the concepts of sustainable development in engineering education. More precisely, a group assignment concerning the topic of climate change was designed for Computers, a first-year subject in the Robotic Engineering degree at the University of Alicante (Spain).

Robots in today's world are helping to improve sustainability efforts in tasks such as monitoring soil conditions, saving transport costs through flexible tele-presence (e.g., in healthcare), monitoring water contamination and air quality, fighting climate change, improving recycling, and making manufacturing sustainable [5]. The purpose of the activity proposed in this paper is to make students reflect about the impact of their work as future engineers on the planet, asking them to design an environmentally friendly robot that also integrated the two other dimensions of sustainability: Society and economy. This type of practice falls into the group of bottom-up approaches to ESD, where action in sustainability issues is taken from the institutional "bottom", i.e., the students [6]. Students' willingness toward sustainable development may play an important role for higher education institutions in promoting campus sustainability. Student commitment is a catalyst for change, building support for new initiatives and applying pressure for change in universities' policies and operations. This vision contrasts with top-down approaches, where change is carried out by administrative leaders by directing their institutions towards greater sustainability through planning and policy-making [7].

Upon completion of the proposed group assignment, a survey was conducted among the students enrolled in the course in order to study different aspects of their commitment, attitudes, practices, and motivation towards sustainability. In addition to the overall analysis of the survey, three specific studies were carried out with the aim of comparing the responses of different population groups: (i) Students who completed the proposed assignment and students who did not, (ii) female and male students, and (iii) roles played in the assignment.

The main research questions addressed in this study are the following:

- $\quad$ RQ1: What are the commitments, attitudes, and practices of Robotic Engineering students with respect to sustainable development?

- RQ2: Are there any differences in attitudes towards sustainability between the students who completed the assignment and those who did not?

- $\quad$ RQ3: Do female and male students have different attitudes towards sustainable development?

- RQ4: Do the roles played in the group assignment influence the students' viewpoints on sustainability issues?

- RQ5: Is sustainable development an engaging topic for Robotic Engineering students?

The rest of this paper is organized as follows: Section 2 presents related work in the field of ESD in higher education; Section 3 describes the context in which this study was carried out: University, degree, subject, and student profile; Section 4 describes the activity designed, including details on some of the proposals developed by the students and a qualitative analysis of their experiences; Section 5 provides information about the survey instrument employed in this work; Section 6 describes and discusses the results of the analysis of the questionnaire; finally, Section 7 presents the conclusions to this study. 


\section{Related Work}

Education has been acknowledged as having a major role in sustainable development [8]. With the 2030 Agenda for Sustainable Development emphasizing that education plays a major role in achieving sustainable development, ESD has received increasing attention from higher education institutions. The goal of higher education for sustainable development is to enable individuals to reflect on their responsibility for the complex effects of decision-making and behavior for a sustainable future [9]. To this end, universities should create teaching and learning settings that support the development of key competencies for dealing with the challenges of sustainable development [10].

Over the last few years, there has been considerable progress in introducing sustainability in higher education institutions at different levels [11]: Institutional frameworks (e.g., policies, visions, and missions) [12], campus operations (e.g., accessibility, energy efficiency, and water management) [13], education (e.g., courses and programs on sustainable development) [14], research (e.g., funding, publications, and patents) [15], outreach and collaboration (e.g., exchange programs for students in the field of sustainable development) [16], and on-campus experiences (e.g., working groups and sustainable practices for students) [17].

At an educational level, a number of learning activities have been reported in the literature to incorporate sustainability in engineering education [18]. Engineering areas covered include Civil [19], Industrial [20], Mechanical [21], Chemical [22], Sanitary [23], and Materials [24]. To the best of the authors' knowledge, there are no previous initiatives of this type reported in the field of Robotic Engineering.

In the context of Spanish higher education, both international reports and diagnostic studies of universities have found that the area in which there are more obstacles and challenges to including sustainability issues is in the education area [25]. Many universities offer specialized courses in ESD and sustainability, but only a few have integrated sustainability into all the degrees in a transversal way so that their students can receive a basic level of instruction in the great challenges of sustainability. A recent study on Spanish higher education institutions analyzed ten curricula from different engineering degrees [26]: Electrical, Informatics, Mechanical, Design, Chemical, and Industrial Technologies. The results of this study indicated that there was no clear strategy for implementing sustainability among the different Spanish universities in terms of the number of subjects in the curricula analyzed. In addition, the presence of sustainability contents was more homogeneous in education degrees than in engineering degrees. These results reflect the importance of carrying out more ESD activities, such as the one described in this paper, in engineering careers.

\section{Context}

The University of Alicante has a strategic plan that presents different actions on sustainability, such as managing air pollution, water saving, or promoting sustainable mobility. All these actions can be considered as campus operation activities, but there are currently no policies on terms of education for sustainability. In this context, it is particularly important to follow a bottom-up approach to ESD by introducing the concepts of sustainability to students in the classroom and surveying them to examine their perception of sustainability issues.

The approach to ESD proposed in this paper was implemented for students of the Robotic Engineering degree at the University of Alicante. The overall goal of this degree is to prepare professionals with a broad and solid training that prepares them to perform engineering tasks in all phases of the life cycle of systems, applications, and products that are related to robotics. Generally speaking, a graduate student in Robotic Engineering is qualified in learning to know and to do in their personal, professional, and social environment, according to the UNESCO report on the prospects of education in the 21st century $[27,28]$.

One of the basic competencies of this degree is that students are able to gather and interpret data (usually within their discipline) to produce reflective opinions on relevant social, scientific, or ethical 
issues. However, there is no specific subject dealing with sustainability issues in the degree, nor a strategy to incorporate it transversally.

The ESD experience presented in this work was carried out in Computers, a first-year subject in the Robotic Engineering degree. Computers are an important part of any robotic system, both as a central core within the internal circuitry of a robot and, in some cases, controlling the robot or other functions from external devices, such as PCs, smartphones, or tablets. The course includes an introduction to the technological foundations and internal structures of computers and their applications to robotics.

Most of the students enrolled in the course were first-year students (around 70\%), aged 18 to 19 . There were a total of 100 students enrolled in the course in 2020, of whom 22 were female students and 78 were male.

\section{Activity Proposal}

This section describes in detail the activity proposed to introduce the concepts of sustainable development in the Robotic Engineering classroom. This description is complemented with a sample of the projects developed by the students and a qualitative analysis of their comments.

\subsection{Description of the Activity}

Active methodologies allow educators to carry out their tasks more effectively, making it easier for students to achieve significant knowledge by being builders and managers of their own learning $[29,30]$. Among active methodologies, cooperative work is a teaching strategy in which students work in small groups on learning activities and are assessed on the productivity of the group. The ESD activity described in this paper consisted of conducting group work on different aspects related to computers in robotics and introducing students to the writing of technical documents. Thus, this work can be situated in the framework of active learning methodologies and assimilated into "problem based learning" [31].

This active learning approach was combined with a role-playing methodology. This pedagogical strategy puts the student in a context that imitates or artificially reproduces some aspects of real life. Within that context, students are expected to handle situations and to solve problems similar to those they would have to face in real conditions [32]. In this way, students participate actively in the construction of their own knowledge, becoming the main characters of the educational process. Students will learn actions, skills, and attitudes that they are likely to use in real life later on. Consequently, role-playing not only allows students to acquire knowledge, investigate, interact, and reflect, but also brings them closer to the reality of their work and professional life [33].

In this work, a procedure has been defined to properly identify, prioritize, and select the different indicators to promote SDGs in the proposed activity (see Figure 1). This procedure can serve as a basis for future works aimed at introducing sustainability in this area. It consists of four steps performed sequentially: (i) Identifying an SDG to act upon, ensuring that the three dimensions (environment, economic cost, and social implications) of the SDG are covered; (ii) defining a case study (activity) for students to solve, encouraging teamwork and open-ended solutions as tools to enhance creativity and learning; (iii) validating the activity by means of a questionnaire for the students, which provides quantitative and qualitative information on the different sustainability aspects of the assignment; (iv) analyzing the feedback from the questionnaire, discussing the most relevant aspects found, and drawing conclusions from the results. 


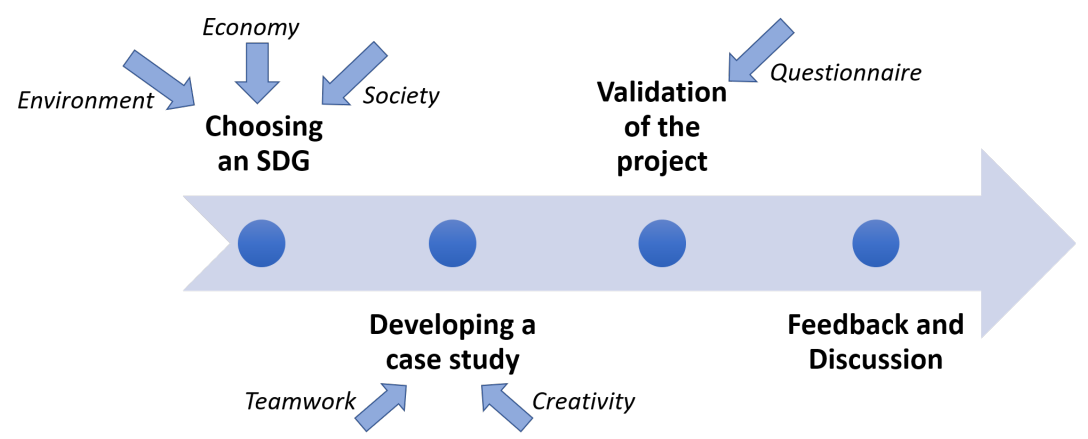

Figure 1. Outline of the procedure followed to define the Sustainable Development Goal (SDG) activity.

In the activity proposed, students were allowed to choose the topic of their project, provided that it was in the area of climate change. Defining an open-ended activity is a common approach to fostering creativity in engineering education. This often involves real-world problems, where students work in teams and the target product is not completely defined in order to allow the future engineers to generate creative ideas [34]. It is estimated that two-thirds of today's grade-school students will end up doing work that has not been invented yet [35]. For engineering students to flourish in this rapidly evolving landscape, the ability to think creatively is essential, even more so in a challenging environment such as that of sustainability.

In open-ended projects, instructors can provide tools to guide students, such as idea templates with guidelines to help students consider important aspects of a problem [36]. For the activity described here, the instructors defined a document identifying the sections that had to be included in the final report submitted by each team:

- Context:

- Specification of where and for what purpose the robot would be used.

- Study of potential users.

- Examples of operating robots that were already doing similar tasks.

- Design of the robot:

- Definition of functional and non-functional requirements.

- Description of the essential internal elements (e.g., sensors, motors, battery, etc.).

- Selection of a microprocessor/microcontroller to be embedded in the system defined above.

- Specification of the shape, building materials, and programming languages of the robot.

- Approximate budget of the robot's cost taking into account the components required.

- Diagram of the robot prototype.

- Use cases and advertising:

- Analysis of market demand.

- Advertising strategies.

- Poster for the final presentation of the proposal in the classroom.

Although the activity addresses all the key competencies for sustainability defined by UNESCO [37], the following list highlights those covered in more depth:

- Systems thinking competency: Students can recognize and understand the relationships between the different components of a robotic system and how to embed sensors, motors, and other components into a standalone system. 
- Anticipatory competency: The proposal of a robot fighting against climate change is an opportunity to design a system with the students' own visions for the future, dealing with the risk of creating new, disruptive systems.

- Strategic competency: This competency is mainly developed through the "use cases and advertising" section of the report, where students explore how their robotic platform can be accepted in local companies and governments, as well as by the general public.

- Collaboration competency: As students play different roles, each of them has to accept others' ideas and respect their decisions, giving their opinions in a proactive way and overcoming conflicts.

- Critical thinking competency: From the beginning of the assignment, students have to think about a project proposal that implies a solution to a challenging problem, trying to develop a technical solution to the important issue that climate change is.

- Self-awareness competency: This competency is developed when students reflect about the role they have in their team and the way they manage their own opinions and feelings about the solution proposed.

- Integrated problem-solving competency: Students deal with a very complex and open problem in the sustainability context using different strategies, and they should develop a solution to a specific problem related to the fight against climate change.

The work developed by the students in this assignment also fulfills different deontological objectives related to attitudes, values, and regulation. According to Lopez et al. [38], students should be able:

- To acquire a real commitment to values such as solidarity, justice, and progress. The proposed activity is an example of acquisition of all three values.

- To acquire an active attitude with regard to the learning process, assuming a leading role in its formation. In the activity, students are organized in teams with different roles and diverse responsibilities so that they acquire an active attitude towards their learning process.

- To increase their awareness with regard to the environment. This coursework makes students reflect on the impact that their work as future engineers can have on the environment.

As mentioned in the introduction, a sustainable solution must address problems in three dimensions: Environmental impact, economic cost, and social implications [39]. The activity proposed here covers all three aspects. For instance, waste materials dumped into the ocean constitute an environmental problem, but in order to find a sustainable robotic solution, students must think about why authorities do not spend enough money to develop a recycling scheme (economic cost) and whether local people understand the impact their actions can have on their children's future lives (social implications). Finding a sustainable solution to the problem involves seeking a balance among these three dimensions of sustainability.

Introducing role-playing mechanisms in the Computers course allowed us to complement the theory sessions, since academic objectives and tasks cannot be achieved or resolved only by using explanatory and illustrative methods. This approach contributes not only to the acquisition of technical knowledge and the development of professional skills, but also to the achievement of motivation for the topics discussed in class. In Figure 2, a graphical description of the roles defined for this assignment is shown. 


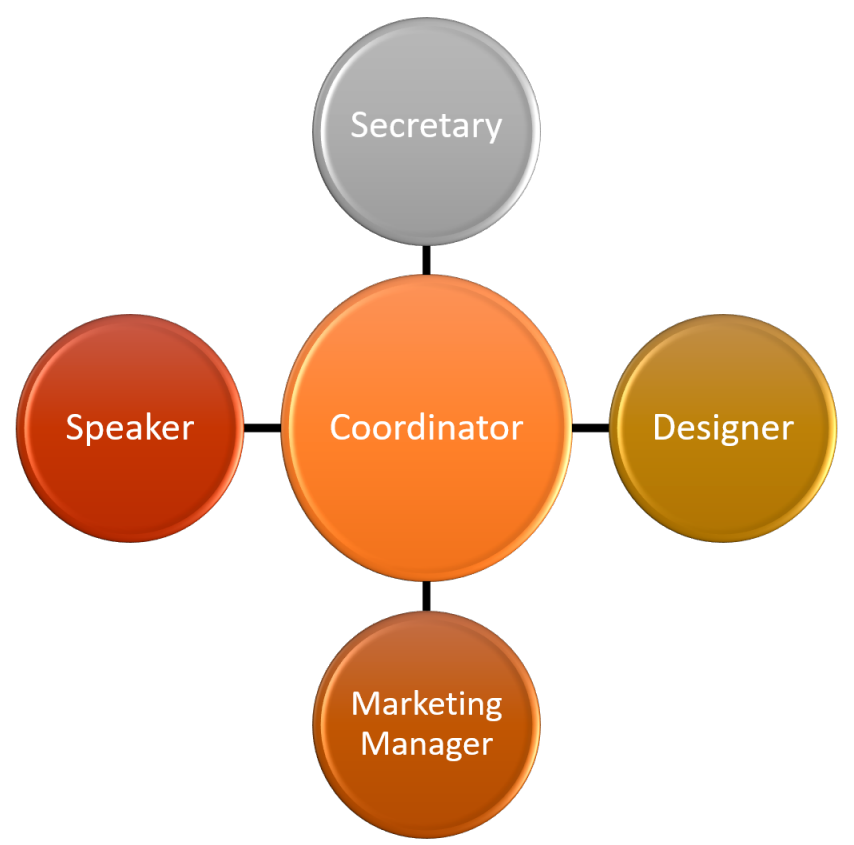

Figure 2. Overview of the roles played in the activity proposed.

The coordinator is the spokesperson in the group. Coordinators assign the roles to the rest of the members of the team and have direct communication with the instructor. The role of the coordinator is the only one voluntarily chosen by the students. They can also select one student to be in their team. The rest of the students are randomly distributed among the teams created. The other roles are defined as follows:

- Secretary: Their main role is to search for information on the topic of the assignment (robots against climate change) and to unify the format of text in the report.

- Designer: They select the components of the robot, estimate the total cost of the proposed system, and write their conclusions on the report.

- Marketing manager: They make a user profile report, perform market research, and investigate how to promote the robot.

- Speaker: Their role is to design a poster of the developed robot in a technical way and present it in a workshop during the last session of the course. They also help the rest of the members of the team in the tasks indicated by the coordinator.

\subsection{Projects Submitted}

A total of 13 groups participated in the activity. Each group consisted of five students, where every student in a group played a different role from the ones mentioned above. Of the total of 100 students enrolled in the course, 35 did not complete the assignment in this course because they already completed a different assignment for the subject in the previous year.

Students developed a wide variety of proposals, some of which are highlighted in the following lines:

- BeeCo: This proposal develops a drone swarm able to autonomously manage waste collection. The drones act like bees when pollinating flowers, collecting dust from exhaust pipes and transporting it to the nearest loading and storage area (the "Honeycomb"). The main objective of this project is to capture toxic particles from exhaust pipes and transform them into ink, achieving healthier air in cities and preventing air pollution (see Figure 3a). 
- Big Wally—a robot for a recycling plant: This project presents a sustainable global initiative that could potentially expand the market for recycled materials. The proposal includes two robotic arms to automatically classify the waste in a recycling plant by means of artificial vision (see Figure $3 \mathrm{~b}$ ).

- BomberBot: The operation of this robot is focused on helping in the prevention and extinguishing of forest fires by using the so-called 30-30-30 rule when predicting fire danger. This rule states that if the wind exceeds 30 kilometers per hour in a given location, there is a humidity of 30 percent or less, and a temperature above 30 degrees, there is a high risk of fire [40]. The robot includes sensors to implement this rule and to predict if there is a high probability of fire in an area (see Figure 3c).

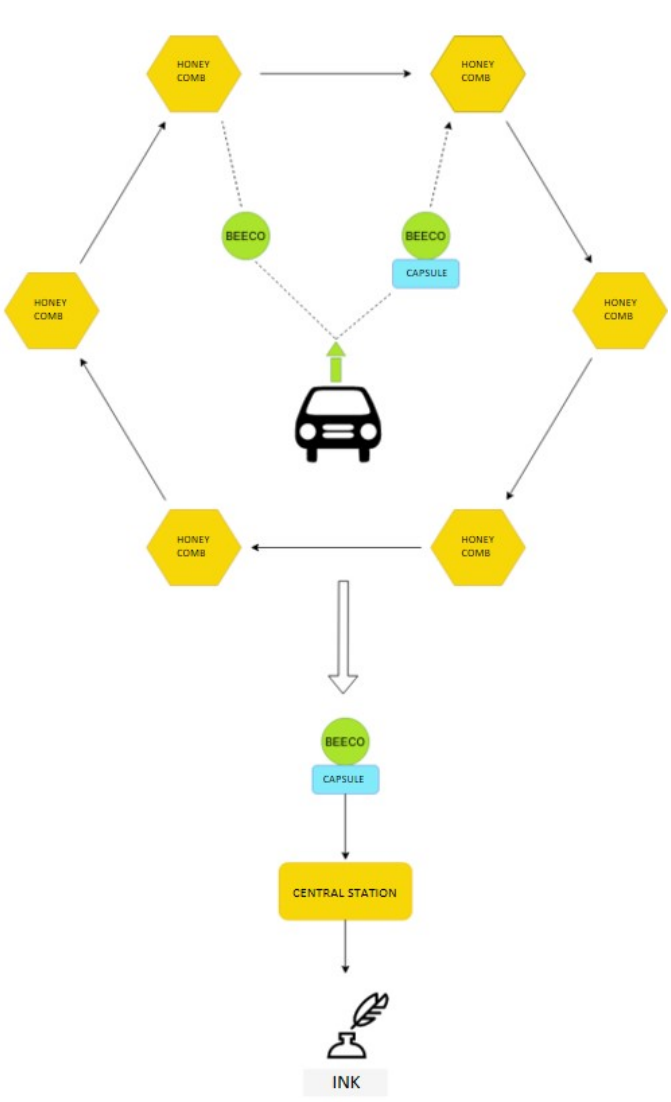

(a)

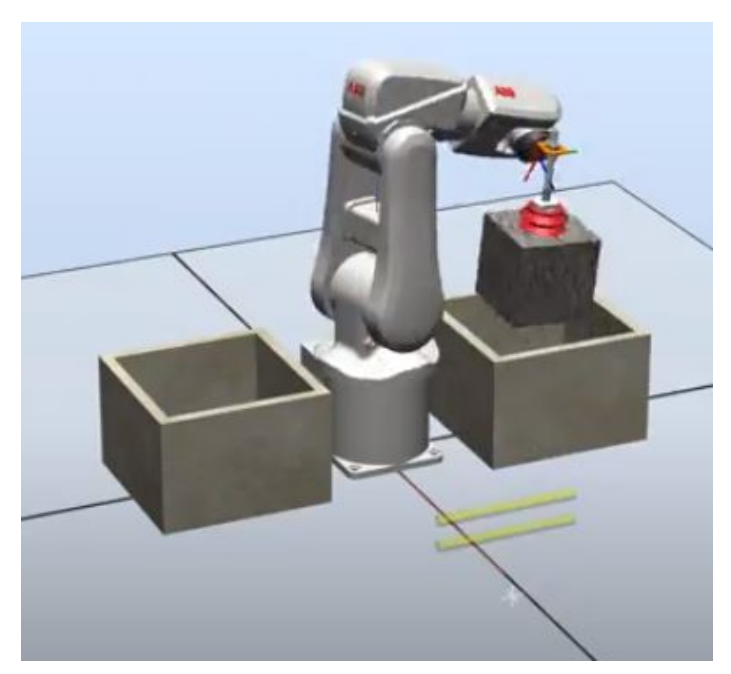

(b)

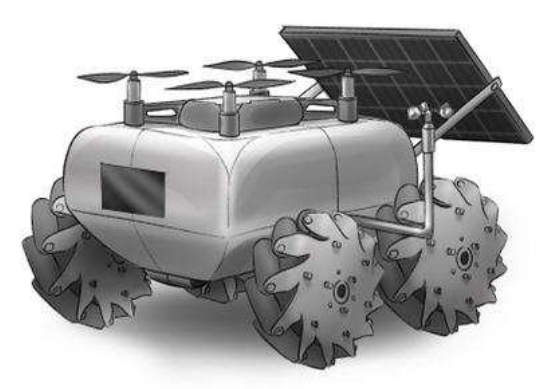

(c)

Figure 3. (a) BeeCo, a robotic bee swarm to prevent air pollution. (b) Big Wally, a recycling robot. (c) Bomberbot, a fire prevention robot.

Other interesting works submitted included: Microclean bot, a robot capable of cleaning the oceans of microplastics; Riparianbot, a robot to control the conditions of rivers and to try to prevent and detect if there is water pollution; and GreenRobot, whose main function is to collect $\mathrm{CO}_{2}$ through a filter for further processing in a factory, recycling the waste for industrial use.

In general, the projects submitted were of very high quality, taking into account that this is a first-year course. The level of involvement of the students and the effort invested in its realization are evident in the final results. In the following sections, the activity developed is analyzed in a quantitative manner, focusing on aspects related to the commitment, attitude, practices, and motivation of the students with respect to sustainable development.

After the project was completed and the survey ended, the qualitative opinions of the students were requested in relation to carrying out such an ambitious project, in which sustainability was a central component of engineering development. The students who expressed their opinion said, 
in general terms, that the development of this work was exciting, and that they learned many concepts from a both a technical and sustainable point of view. They also pointed out that this was a very important topic within sustainable development, which certainly motivated them. In fact, they considered it extremely important to continue working on similar topics or including applications of robotics related to sustainability throughout the degree.

Generally speaking, students expressed that, through the work that they carried out, they were able to face the challenges of designing and planning a robotic prototype. However, the thing they valued the most was having had the opportunity of proposing a solution to a difficult issue in sustainable development, such as combating climate change, since it allowed them to acquire an actual awareness of sustainability issues. Being able to determine possible solutions to this environmental problem by making use of different technological advances allowed them to "achieve a perfect link between the world of technology and the natural world", in their own words.

Some of the positive comments made by the students in the open-ended section of the questionnaire were the following:

- "This work was very exciting. I have learned a lot of things both from the technical side and from the sustainability side. Thank you very much."

- "The work was a challenge for me, and I have discovered a very interesting field in robotics."

- "It was a very interesting topic, and one that made me know that there are more problems than we think with respect to climate change. There are various robotic solutions proposed, but most are not implemented."

- "It is a very important topic that has undoubtedly motivated me to devote time and effort to work on this subject. No doubt, it is something that the whole class liked, and we would not mind continuing to work on similar topics, even if it is outside of class hours."

- "It is a topic that worries me a lot and I think it is important that these ideas are raised by the university."

\section{Survey Instrument}

The survey instrument used in this study is an adaptation of the questionnaire validated in [41], which was based on the works by [42,43] on assessing students' personal commitment and their perceptions about universities' achievements in different dimensions of sustainable development.

The questionnaire was published upon students' submission of the report on the assignment. The nature of participation was voluntary and the information gathered from respondents was treated confidentially. The survey was available for one week to all of the students enrolled in the subject, including those taking the subject for a second time who did not participate in the assignment because they passed this part in the previous year. The opinions of these students were especially valuable in order to determine whether doing the assignment or not had any influence on the perception of sustainability issues, as discussed in Section 6.3.

The original questionnaire was translated into Spanish to match the language profile of the respondents, and was adapted conveniently to situate the questions in the context of the University of Alicante and the Robotic Engineering degree where necessary. A set of five questions was removed from the proposal by [41] and a new one was added at the end of the survey. The dismissed questions included the complete section devoted to testing the students' knowledge about sustainability issues, which was outside the scope of this study. The new question introduced had the purpose of gathering feedback about how motivational it was for the students to work in a topic related to sustainability in the assignment proposed.

In the survey, there was an initial set of questions concerned with the demographic information of the students: Age, gender, number of years enrolled in the subject (there are repeaters), and role in the team (coordinator, designer, etc.). 
The questionnaire was divided into six different sections, as shown in Table 1. The first one consisted of three questions, investigating the students' commitment towards sustainable development. The second section focused on exploring the attitude of the students towards the implications of the university in promoting sustainable development. The third section inquired about the presence of sustainable principles in the curricula of the degree and the research at the university. The fourth section explored the respondents' involvement in campus sustainability, whereas the fifth asked about sustainable practices, such as recycling, energy-saving habits, and green transportation. Finally, the last section included a single question that, as mentioned above, revolved around the motivation of the students when working on an assignment dealing with sustainable development issues. The answers to all these questions consisted of a five-point Likert scale, ranging from 1 (strongly disagree) to 5 (strongly agree). The survey form also contained an open-ended section for comments.

Table 1. Sustainable development questionnaire given to the students.

Commitment towards sustainable development

1. I am concerned about the wasteful consumption of natural resources and the destruction/pollution of the environment.

2. I believe that the protection of the environment is more important than economic growth.

3. I believe that we must conserve our resources for future generations.

\section{University's role in sustainability}

4. I believe that the University of Alicante should make sustainability a priority in campus planning, development, and day-to-day operations.

5. I believe that the University of Alicante should contribute to social well-being, tolerance, and fulfillment of the needs of disabled people.

6. I believe that everyone in the University of Alicante should support sustainable solutions to environmental problems.

\section{Curriculum and research covering sustainability}

7. I believe that the University of Alicante needs to offer courses that address topics related to sustainability.

8. I believe that the University of Alicante needs to integrate sustainability aspects into the Robotic Engineering degree program.

9. I believe that the University of Alicante needs to promote research and projects related to environmental sustainability.

\section{Student's involvement in campus sustainability}

10. I want to help to create a sustainable campus.

11. I am interested in taking part in social activities (such as volunteering) related to sustainability organized by the University of Alicante.

12. I will support and participate in the University of Alicante's initiatives to protect the environment.

Practices for sustainable development

13. I usually recycle.

14. I take measures in my daily life to save energy.

15. I use ecological products.

16. I use green transportation (e.g., bicycle, electric vehicles, etc.).

17. I need to change my current energy use practices to be more sustainable.

\section{About the assignment}

18. Doing group work that involves aspects of sustainable development, such as climate change, has been motivational for me.

\section{Results and Discussion}

This section presents and discusses the main findings of the analysis of the survey. The study carried out in this section covers three different configurations of the respondent group:

- $\quad$ Students who did the assignment and students who did not (Section 6.3). 
- Female and male students (Section 6.4).

- Roles played by the students in the working group (Section 6.5).

For the statistical analysis, the frequency distribution was calculated for each question using the percentage as the way to represent it. To identify whether or not there was a statistically significant difference between distributions, the two-tailed independent $t$-test was carried out, with a significance level of $\rho=0.05$.

Before analyzing the three settings mentioned above, a summary of the demographic characteristics is presented, followed by an overall analysis of the survey.

\subsection{Demographic Characteristics of Respondents}

As mentioned in Section 5, the demographic variables requested in the questionnaire were: Age, gender, number of years enrolled in the subject, (there is a maximum of three years, imposed by regulations, in which a student can be enrolled in a subject at the University of Alicante), and role in the working group. The distribution of these variables is shown in Table 2, indicating the number and percentage of responses of each type.

Table 2. Demographics of respondents.

\begin{tabular}{lrl}
\hline Age & 32 & $(58.18 \%)$ \\
\hline 18 & 10 & $(18.18 \%)$ \\
19 & 1 & $(1.82 \%)$ \\
20 & 12 & $(21.82 \%)$ \\
$21>$ & & \\
\hline Gender & 34 & $(61.82 \%)$ \\
\hline Male & 21 & $(38.18 \%)$ \\
Female & & \\
\hline Years enrolled & & \\
\hline One & 42 & $(76.36 \%)$ \\
Two & 11 & $(20.00 \%)$ \\
Three & 2 & $(3.64 \%)$ \\
\hline Role in the group & & \\
\hline Coordinator & 13 & $(23.64 \%)$ \\
Secretary & 6 & $(10.91 \%)$ \\
Designer & 12 & $(21.82 \%)$ \\
Marketing & 5 & $(9.09 \%)$ \\
Speaker & 8 & $(14.55 \%)$ \\
Did not participate & 11 & $(20.00 \%)$ \\
\hline & &
\end{tabular}

Of the 100 enrolled in the course, a total of 55 students responded to the questionnaire. Most of them were first-year students $(76.36 \%)$ aged 18 years $(58.18 \%)$. There were more male respondents $(61.82 \%)$ than female $(38.18 \%)$, but this value is conditioned by the unbalanced enrollment between men and women in Science, Technology, Engineering, and Math (STEM)-related degrees, as further discussed in Section 6.4.

The question regarding the role in the group sought not only to identify this variable, but also to spot respondents that did not complete the proposed assignment, labeled in the previous table as "Did not participate" ( $20 \%$ of the total). Of those who completed the assignment, the more active participants in the survey were coordinators $(23.64 \%)$ and designers $(21.82 \%)$. At this point, it is important to recall that the number of students in each role was evenly distributed, since every group included one of these five figures. 


\subsection{Overall Analysis}

The following paragraphs describe the overall results obtained in the questionnaire, analyzing the distribution of responses for each of the items in the instrument.

Table 3 summarizes these values. The first column indicates the number of the question, as stated in Table 1. The second column is the mean $(M)$ of all the responses (considering a five-point Likert scale) for each item. Higher values indicate greater agreement. The third column includes the standard deviation $(S D)$ for each response. The last three columns group the Likert scale responses into categories, where Agree indicates a value of 4 or 5, Undecided implies a value of 3, and Disagree stands for a value of 1 or 2 . These columns reflect the percentages of responses that fall into each of these categories.

Table 3. Distribution of responses for each of the questions in the survey.

\begin{tabular}{|c|c|c|c|c|c|}
\hline Question & $\mathbf{M}$ & SD & Agree & Undecided & Disagree \\
\hline \multicolumn{6}{|c|}{ Commitment towards sustainable development } \\
\hline 1 & 4.38 & 0.65 & $90.91 \%$ & $9.09 \%$ & $0.00 \%$ \\
\hline 2 & 3.75 & 1.04 & $67.27 \%$ & $20.00 \%$ & $12.73 \%$ \\
\hline 3 & 4.55 & 0.74 & $92.73 \%$ & $3.64 \%$ & $3.64 \%$ \\
\hline \multicolumn{6}{|c|}{ University's role in sustainability } \\
\hline 4 & 4.06 & 1.15 & $74.55 \%$ & $14.55 \%$ & $10.91 \%$ \\
\hline 5 & 4.58 & 0.79 & $90.91 \%$ & $7.27 \%$ & $1.82 \%$ \\
\hline 6 & 4.45 & 0.86 & $89.09 \%$ & $7.27 \%$ & $3.64 \%$ \\
\hline \multicolumn{6}{|c|}{ Curriculum and research covering sustainability } \\
\hline 7 & 3.72 & 1.37 & $65.45 \%$ & $14.55 \%$ & $20.00 \%$ \\
\hline 8 & 3.60 & 1.34 & $60.00 \%$ & $18.18 \%$ & $21.82 \%$ \\
\hline 9 & 4.25 & 0.75 & $85.45 \%$ & $12.73 \%$ & $1.82 \%$ \\
\hline \multicolumn{6}{|c|}{ Student's involvement in campus sustainability } \\
\hline 10 & 4.02 & 0.91 & $74.55 \%$ & $18.18 \%$ & $7.27 \%$ \\
\hline 11 & 3.45 & 1.23 & $50.91 \%$ & $29.09 \%$ & $20.00 \%$ \\
\hline 12 & 3.80 & 1.03 & $70.91 \%$ & $20.00 \%$ & $9.09 \%$ \\
\hline \multicolumn{6}{|c|}{ Practices for sustainable development } \\
\hline 13 & 4.16 & 1.15 & $76.36 \%$ & $14.55 \%$ & $9.09 \%$ \\
\hline 14 & 4.29 & 0.92 & $87.27 \%$ & $9.09 \%$ & $3.64 \%$ \\
\hline 15 & 3.09 & 1.04 & $30.91 \%$ & $41.82 \%$ & $27.27 \%$ \\
\hline 16 & 3.09 & 1.44 & $49.09 \%$ & $9.09 \%$ & $41.82 \%$ \\
\hline 17 & 3.49 & 1.14 & $50.91 \%$ & $30.91 \%$ & $18.18 \%$ \\
\hline \multicolumn{6}{|c|}{ About the assignment } \\
\hline 18 & 3.88 & 1.72 & $63.64 \%$ & $7.27 \%$ & $29.09 \%$ \\
\hline
\end{tabular}

The first section of the table (questions 1 to 3) presents the results of commitment towards sustainable development. The results reveal that the majority of the students agreed that they were concerned with the consumption of natural resources and the pollution of the environment $(90.91 \%)$, to the extent that no one disagreed on that. They also believed that people must conserve existing resources for future generations (92.73\%). There is less agreement in question 2, related to the balance between environmental protection and economic growth. In this case, $67.27 \%$ agreed on the prevalence of environmental over economic interests, but the remainder $(32.73 \%)$ stood undecided about or disagreed on this point. This is an expected result for such a controversial issue, especially taking into account the concerns about the future job market that every student faces during their career.

The second part of the questionnaire, covering items 4, 5, and 6, examines students' perceptions regarding the role of their university in promoting sustainable development. Around three out of four 
students $(74.55 \%)$ agreed that the University of Alicante should prioritize sustainability in campus planning and development. The other two questions, covering the contribution of their university to social good and the support of their staff for sustainable solutions, achieved $90.91 \%$ and $89.09 \%$ agreement, respectively.

When asked about the role of the curriculum and research in sustainability (items 7, 8, and 9), $65.45 \%$ agreed on the importance of the university offering courses that address topics related to sustainability, and $60 \%$ agreed on the inclusion of these topics in the Robotic Engineering degree program. Although these figures are lower than the agreement values obtained in the previous sets of questions, they are remarkably higher than the results obtained in the study carried out by Wang et al. [41], where 42.8\% (Zhongkai University of Agriculture and Engineering) and 47.6\% (Guangzhou College of South China University of Technology) of the students agreed on the first question, and 29.5\% (Zhongkai) and 44.1\% (Guangzhou) agreed on the second one. The final question in this block addressed the importance of promoting research and projects related to environmental sustainability, which was agreed upon by $85.45 \%$ of the responses, again significantly higher than their Chinese counterparts, who agreed in 29\% (Zhongkai) and 19.3\% (Guangzhou) of the cases.

In the following block of questions $(10,11$, and 12), the focus was in examining students' personal involvement in making a more sustainable campus. Around three-quarters of the respondents $(74.55 \%)$ expressed their agreement on helping to create a sustainable campus. This figure was notably reduced when the students were asked about active participation in volunteering activities, obtaining $50.91 \%$ agreement, the lowest value in this study so far. The agreement rose again when asked about support and participation in initiatives to protect the environment, obtaining $70.91 \%$.

The next five questions $(13,14,15,16$ and 17) investigate respondents' perceptions about their own practices for sustainable development. Recycling (item 13) is a practice that has been rooted in today's society, and many young citizens agree on the relevance of this habit, as reflected by the $76.36 \%$ agreement rate in the questionnaire. In addition, saving energy is a common practice in the group studied, since $87.27 \%$ responded that they take measures in their daily lives to save energy. The use of ecological products was rather limited, only agreed upon in $30.91 \%$ of the answers. Finally, $49.09 \%$ respondents claimed to use green transportation, and $50.91 \%$ think that they have to change any of their current energy use practices to be more sustainable. In this last question, $30.91 \%$ of the answers were undecided, reflecting that a significant number of the respondents probably ignore whether their daily practices affect the environment or not, suggesting again the relevance of introducing ESD initiatives to improve the awareness of sustainability issues in students. The results of this part of the questionnaire are in line with a past study promoted by the European Commission on the attitudes towards sustainable consumption and production [44]. This survey revealed that $37 \%$ of Spanish people thought that minimizing waste and recycling are the actions that have the greatest impact on solving environmental problems—-seven points above the European average-whereas only $19 \%$ considered using eco-friendly products as the most important action, two points below the European average.

The last question in Table 3 asks about the motivational aspects of working on the group assignment proposed in the area of sustainable development. Almost two-thirds (63.64\%) of the students agreed that the topic of climate change was an extra motivation for them when addressing their coursework. This result is encouraging, since adding the sustainability topic to the curriculum cannot only be a way to influence the awareness of students on this issue, but it can also be a mechanism to motivate them in their classroom activities.

The results provided in the previous table show that the three best-valued questions were:

5. I believe that the University of Alicante should contribute to social well-being, tolerance, and fulfillment of the needs of disabled people $(M=4.58, S D=0.79)$.

3. I believe that we must conserve our resources for future generations $(M=4.55, S D=0.74)$.

6. I believe everyone in the University of Alicante should support sustainable solutions to environment problems $(M=4.45, S D=0.86)$. 
Questions 5 and 6 belong to the category of the university's commitment towards sustainable development. This reflects that students believe that their university should commit to social good and sustainable development as a priority. Regarding question 3, this falls into the category of students' personal commitment towards sustainable development, reflecting their awareness of the resource consumption problem for future generations. The comparison with their Chinese counterparts [41] indicates that both coincide in the relevance of question 3 , which was given the highest score in that study. Question 5 ranked in position 6, and question 6 ranked in position 10.

In contrast, the three questions that obtained the lowest values were:

15. I use ecological products $(M=3.09, S D=1.04)$.

16. I use green transportation (e.g., bicycle, electric vehicles, etc.) $(M=3.09, S D=1.44)$.

11. I am interested in taking part in social activities (such as volunteering) related to sustainability organized by the University of Alicante $(M=3.45, S D=1.23)$.

The two lowest-valued items, questions 15 and 16, belong to the category of practices for sustainable development. This reflects that there is a large margin for the students to improve their sustainability habits, and that activities such as the one proposed in this work can have an impact on them. Question 11 belongs to the category of students' involvement in campus sustainability, and indicates that active participation and volunteering are a pending issue for the respondents. Students seem to have, at the same time, both a high concern about sustainable development issues (as indicated by the strong agreement with most of the questions) but a poor attitude towards actively addressing this problem. This contradiction may be due to the lack of awareness of the key role they can play in sustainable development as future engineers. The integration of more activities related to ESD in engineering degrees is thus necessary so that students can become aware of the impact of their work in the future of the planet.

\subsection{Participation Analysis}

The focus of this section is to contrast the responses to the questionnaire between those students who did the assignment and those who did not, verifying if there are any differences in the perception of sustainability issues between these two groups. Thus, the null hypothesis here is that there is no difference in the responses given to the questionnaire whether the student did the assignment or not.

From the total number of respondents, 44 students did the assignment $(80 \%)$ and 11 did not $(20 \%)$. On the one hand, there were 65 students enrolled in the course who did the assignment, which implies that $67.69 \%$ of them answered the questionnaire. On the other hand, $31.43 \%$ of the 35 students who did not do the assignment completed the survey. These values reflect from the start that students who carried out the activity were more interested in answering a questionnaire about sustainable development.

Table 4 shows the mean, standard deviation, $t$-test, and $\rho$ for each of the questions of the survey. Group A includes students who did the assignment, whereas Group B refers to those who did not. Question 18 is omitted in the results, since only students belonging to Group A did the assignment. The $\rho$ value is boldfaced when differences between groups are statistically significant $(\rho<0.05)$.

These results show that, in only one of the questions, the difference between groups is statistically significant. In question 16, related to the use of green transportation, the 44 participants who did the assignment $(M=3.34, S D=1.43)$, compared to the 11 participants in Group B $(M=2.09, S D=1.04)$, demonstrated significantly better results: $t(53)=2.72, \rho=0.009$. Although statistically significant, this result is not practically significant, since it does not provide strong insights on the effect of doing the assignment or not on the sustainability concerns of the students; differences in the habits of walking, cycling, or car sharing can be due to many other circumstances (e.g., proximity to the University, attitude towards sports, or saving money). In the rest of the items, higher scores fluctuated between Group A and Group B, but there was no significant effect for this condition. 
One of the problems of the analysis proposed in this section is the unbalanced distribution of participants in each group ( $80 \%$ in Group A and $20 \%$ in Group B). This situation makes it difficult to achieve significant results in the statistical tests carried out. For future work, in order to better analyze the effects of doing the assignment, a previous survey should be delivered to the students in order to compare pre-assignment and post-assignments conditions, performing a dependent $t$-test to see whether the attitudes changed after carrying out the coursework.

The conclusion on this first analysis is that there is no significant difference in the commitment towards sustainability between those who did the assignment and those who did not. In any case, this results do not dismiss the beneficial effects that this kind of practice can have on the motivation of the students. As reflected in the previous section, $63.64 \%$ of the students from Group A agreed that the topic of climate change was a motivational subject for them.

Table 4. Comparison between students that did the assignment (Group $A$ ) and those who did not (Group B), showing the mean $(M)$, standard deviation $(S D), t$-test, and $\rho$ values for each question.

\begin{tabular}{|c|c|c|c|c|c|c|}
\hline \multirow[b]{2}{*}{ Question } & \multicolumn{2}{|c|}{ Group A } & \multicolumn{2}{|c|}{ Group B } & \multirow[b]{2}{*}{$t$-test } & \multirow[b]{2}{*}{$\rho$} \\
\hline & $\mathbf{M}$ & SD & $\mathbf{M}$ & SD & & \\
\hline \multicolumn{7}{|c|}{ Commitment towards sustainable development } \\
\hline 1 & 4.34 & 0.64 & 4.55 & 0.69 & -0.93 & 0.357 \\
\hline 2 & 3.66 & 1.10 & 4.09 & 0.70 & -1.24 & 0.221 \\
\hline 3 & 4.59 & 0.62 & 4.36 & 1.12 & 0.91 & 0.368 \\
\hline \multicolumn{7}{|c|}{ University's role in sustainability } \\
\hline 4 & 3.95 & 1.08 & 4.50 & 1.45 & 1.55 & 0.127 \\
\hline 5 & 4.59 & 0.79 & 4.55 & 0.82 & 0.170 & 0.866 \\
\hline 6 & 4.36 & 0.92 & 4.82 & 0.40 & -1.60 & 0.116 \\
\hline \multicolumn{7}{|c|}{ Curriculum and research covering sustainability } \\
\hline 7 & 3.64 & 1.45 & 4.00 & 0.89 & -1.13 & 0.262 \\
\hline 8 & 3.59 & 1.40 & 3.64 & 1.12 & -0.10 & 0.921 \\
\hline 9 & 4.20 & 0.79 & 4.45 & 0.52 & -0.99 & 0.328 \\
\hline \multicolumn{7}{|c|}{ Student's involvement in campus sustainability } \\
\hline 10 & 4.05 & 0.96 & 3.91 & 0.70 & 0.44 & 0.662 \\
\hline 11 & 3.48 & 1.32 & 3.36 & 0.81 & 0.27 & 0.787 \\
\hline 12 & 3.75 & 1.10 & 4.00 & 0.63 & -0.72 & 0.475 \\
\hline \multicolumn{7}{|c|}{ Practices for sustainable development } \\
\hline 13 & 4.09 & 1.22 & 4.45 & 0.82 & -0.93 & 0.353 \\
\hline 14 & 4.25 & 0.97 & 4.45 & 0.69 & -0.66 & 0.513 \\
\hline 15 & 3.11 & 1.08 & 3.00 & 0.89 & 0.32 & 0.749 \\
\hline 16 & 3.34 & 1.43 & 2.09 & 1.04 & 2.72 & 0.009 \\
\hline 17 & 3.43 & 1.17 & 3.73 & 1.01 & -0.76 & 0.446 \\
\hline
\end{tabular}

\subsection{Gender Analysis}

Traditionally, there has been a gender imbalance in Science, Technology, Engineering, and Math (STEM) careers [45]. Many different initiatives have tried to bridge this gap world-wide, such as Women Who Code (https:/ / www.womenwhocode.com), Women's Engineering Society ( https:// www.wes.org.uk), The European Association for Women in Science, Technology, Engineering and Mathematics (WiTEC EU, https:/ / www.witeceu.com), Women into Science and Engineering (WISE, https:/ /www.wisecampaign.org.uk), and Robogals. (https://robogals.org). One of the approaches that has been demonstrated to attract and engage women in STEM careers is to present these fields as tools for solving problems that matter, especially those related to social good [46]. This section analyzes and compares the responses of the questionnaire for female and male students. The aim is to 
test if there are different concerns between groups on sustainability development issues, and also with respect to the activity proposed.

There were 22 female and 78 male students enrolled in the course. The questionnaire was answered by 21 female and 34 male students. A chi-square test of independence was performed to examine the relation between gender and the willingness to answer the survey. The relation between these variables was significant- $\chi^{2}(1, N=100)=18.65, \rho<0.001-$ reflecting that female students were more likely than their male counterparts to answer the survey. This already reflects a difference in attitude between the two groups.

As in the previous section, Table 5 shows the mean, standard deviation, $t$-test, and $\rho$ for each of the questions of the survey.

The results on commitment towards sustainable development reflect no significant effect for gender, despite female students attaining higher scores than male students in the three questions of this section. The same happens with respect to the university's role in sustainability, although in this case, question 5 presents significantly better results at level 0.10 , with $t(53)=1.72$ and $\rho=0.091$.

The responses on curriculum and research covering sustainability present more clear differences between the two groups. In question 7, when asked about the need for their university to offer courses that address the topic of sustainability, the female group $(M=4.30, S D=1.34)$ answered with significantly higher values— $t(53)=2.95, \rho=0.005$-than the male group $(M=3.36, S D=1.31)$. Questions 8 and 9 were also significant, but at level 0.10, obtaining $t(53)=2.00, \rho=0.051$ and $t(53)=1.75, \rho=0.085$, respectively.

Table 5. Comparison between Female and Male students, showing the mean $(M)$, standard deviation $(S D), t$-test, and $\rho$ values for each question.

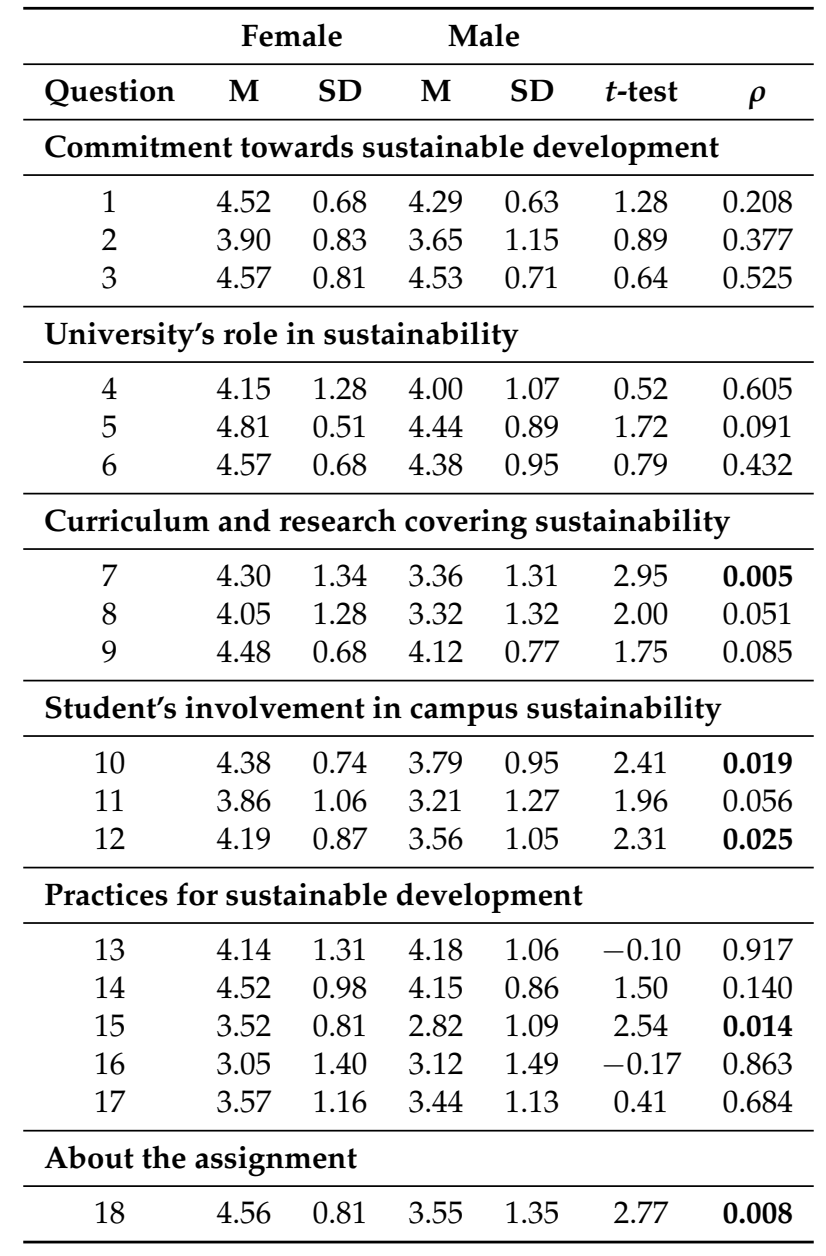


As in the previous block of items, there are statistically significant differences between both groups regarding students' involvement in campus sustainability. In question 10 , the female group $(M=4.38$, $S D=0.74)$ answered significantly higher than the male group $(M=3.79, S D=0.95)-t(53)=2.41$, $\rho=0.019$-demonstrating more willingness in helping to create a sustainable campus. Question 11, asking about taking part in social activities and volunteering, presents differences at significance level 0.10 , again with female students being more committed, $t(53)=1.96, \rho=0.056$. The last question of this block, asking about support and participation in the university's initiatives to protect the environment, shows a statistically significant difference in favor of female students- $t(53)=2.31$, $\rho=0.025$. The results in this section of the survey reveal significant differences between the two groups, emphasizing that female students have a higher commitment towards getting actively involved in creating a sustainable campus.

From the five questions related to the actual practices of students for sustainable development, only one of them presented significant differences between the two groups. Item 15, asking about the use of ecological products, showed higher values for the female group, $t(53)=2.54, \rho=0.014$. Male students obtained slightly higher values for recycling (question 13) and green transportation (question 16) habits. These are the only two items of the questionnaire where male students obtained higher values than their female counterparts, although the difference is not statistically significant.

Finally, answers to question 18 show a result in line with those obtained in the previous items. The female group $(M=4.56, S D=0.81)$, compared to the male group $(M=3.55, S D=1.35)$, significantly agreed more about being motivated by the introduction of the climate change topic in the assignment, $t(53)=2.77, \rho=0.008$. As mentioned at the beginning of this section, topics related to social good can be an incentive and a way to attract and retain female talent in STEM careers. In this sense, the ESD activity proposed in this study is not only a way to introduce sustainable concepts into the classroom, but also a way to motivate female students. Regarding the male group, although the results are not as encouraging in terms of the motivation achieved, an analysis of the distribution of their responses shows that $59 \%$ of students agreed (i.e., answered with 4 or 5 on the Likert scale) on the motivational aspects of the activity, more than double those who disagreed (29\%). The remaining $12 \%$ were undecided.

\subsection{Role Analysis}

As previously mentioned, the activity proposed was carried out in groups of five students, each of them with a different role in the team. This section analyzes the answers provided grouped by role, trying to determine if there exists a relation between the role played in the group and the concern and motivation regarding sustainable development.

The students formed 13 working groups to develop the activity, which implies that there were 13 students assigned to each role. Table 2 summarized the number of respondents by role: 13 coordinators, 6 secretaries, 12 designers, 5 marketing managers, and 8 speakers. A chi-square test of independence was performed to examine the relation between completing the questionnaire and the role in the group. Although the differences in the number of respondents per role were large in some cases, the relation between these variables was not significant $-\chi^{2}(4, N=75)=3.9$, $\rho=0.42$-indicating that the role played did not have an influence on answering the questionnaire.

Unlike the two previous analyses, in this section, five different groups of students are compared. The previous $t$-test statistic is now substituted with one-way analysis of variance (ANOVA) [47]. In cases where the result of the ANOVA is significant, Tukey's HSD (honestly significant difference) post-hoc test is used to assess which pairs of groups differ significantly [48].

Table 6 summarizes the mean and standard deviation for each role, with the last two columns showing the $f$ statistic and $\rho$ of the ANOVA test.

In the first block, the results of ANOVA are significant for questions 2 and 3. Firstly, Tukey's HSD post-hoc test identifies that the responses of designers are significantly higher than those of secretaries $(\rho=0.037)$. Secondly, values reported by designers are higher than those of speakers 
( $\rho=0.024)$. Thus, in both cases, students playing the role of designer presented higher commitment. The difference between designer and secretary takes place again in question 8 , when asked about the need to integrate sustainability into the degree program $(\rho=0.024)$. Finally, question 10 also presents statistically significant differences between two of the groups, secretaries and speakers $(\rho=0.013)$, who were the first to demonstrate a better attitude towards helping to create a sustainable campus.

In addition to the results provided by this analysis, the perception of the teachers during the implementation of the activity is that some roles implied more responsibility and commitment than others in the final outcome. This is the case of coordinators and designers, who were more active and involved in the activity than speakers and secretaries, with marketing managers at an intermediate position. Although the results of this section do not allow the formulation of a strong statement about the relation between the role played and the awareness about sustainable development, they suggest that the degree of responsibility acquired in the development of the activity may influence the subsequent commitment. This detail should be taken into account in the future for activities attempting to engage students in sustainable development by trying to evenly distribute the responsibility between all the members of the group to make the activity more beneficial for all.

Table 6. Comparison between roles, showing mean (M), standard deviation $(S D), f$ statistic, and $\rho$ values for each question.

\begin{tabular}{|c|c|c|c|c|c|c|c|c|c|c|c|c|}
\hline \multirow[b]{2}{*}{ Question } & \multicolumn{2}{|c|}{ Coordinator } & \multicolumn{2}{|c|}{ Secretary } & \multicolumn{2}{|c|}{ Designer } & \multicolumn{2}{|c|}{ Marketing } & \multicolumn{2}{|c|}{ Speaker } & \multirow[b]{2}{*}{$f$} & \multirow[b]{2}{*}{$\rho$} \\
\hline & $\mathbf{M}$ & SD & $\mathbf{M}$ & SD & $\mathbf{M}$ & SD & $\mathbf{M}$ & SD & $\mathbf{M}$ & SD & & \\
\hline \multicolumn{13}{|c|}{ Commitment towards sustainable development } \\
\hline 1 & 4.23 & 0.73 & 4.33 & 0.52 & 4.50 & 0.67 & 4.20 & 0.84 & 4.38 & 0.52 & 0.32 & 0.862 \\
\hline 2 & 3.31 & 1.18 & 2.67 & 1.21 & 4.17 & 0.72 & 3.80 & 0.84 & 4.13 & 0.99 & 3.08 & 0.027 \\
\hline 3 & 4.69 & 0.48 & 4.67 & 0.52 & 4.83 & 0.39 & 4.60 & 0.55 & 4.00 & 0.93 & 2.76 & 0.041 \\
\hline \multicolumn{13}{|c|}{ University's role in sustainability } \\
\hline 4 & 3.85 & 1.34 & 3.67 & 1.21 & 4.33 & 0.78 & 4.40 & 0.55 & 3.50 & 1.07 & 1.09 & 0.375 \\
\hline 5 & 4.38 & 1.19 & 4.67 & 0.52 & 4.83 & 0.39 & 4.80 & 0.45 & 4.38 & 0.74 & 0.74 & 0.569 \\
\hline 6 & 4.23 & 1.17 & 3.83 & 1.17 & 4.50 & 0.67 & 4.60 & 0.55 & 4.63 & 0.74 & 0.87 & 0.490 \\
\hline \multicolumn{13}{|c|}{ Curriculum and research covering sustainability } \\
\hline 7 & 3.75 & 1.66 & 2.67 & 1.63 & 4.09 & 1.42 & 3.60 & 1.14 & 3.63 & 1.30 & 1.30 & 0.289 \\
\hline 8 & 3.62 & 1.61 & 2.17 & 1.60 & 4.25 & 0.97 & 4.00 & 1.00 & 3.38 & 1.06 & 2.75 & 0.042 \\
\hline 9 & 4.38 & 0.77 & 3.50 & 1.05 & 4.17 & 0.58 & 4.20 & 1.10 & 4.50 & 0.53 & 1.74 & 0.161 \\
\hline \multicolumn{13}{|c|}{ Student's involvement in campus sustainability } \\
\hline 10 & 4.08 & 0.95 & 3.00 & 1.26 & 4.17 & 0.72 & 4.00 & 1.00 & 4.63 & 0.52 & 3.02 & 0.029 \\
\hline 11 & 3.46 & 1.56 & 2.67 & 1.63 & 3.58 & 1.31 & 3.80 & 0.84 & 3.75 & 0.89 & 0.73 & 0.580 \\
\hline 12 & 3.77 & 1.30 & 2.83 & 1.60 & 3.92 & 0.79 & 4.00 & 0.71 & 4.00 & 0.76 & 1.31 & 0.283 \\
\hline \multicolumn{13}{|c|}{ Practices for sustainable development } \\
\hline 13 & 4.00 & 1.41 & 5.00 & 0.00 & 4.08 & 0.90 & 4.60 & 0.55 & 3.25 & 1.58 & 2.27 & 0.079 \\
\hline 14 & 3.85 & 1.41 & 3.67 & 0.82 & 4.50 & 0.52 & 4.80 & 0.45 & 4.63 & 0.52 & 2.25 & 0.081 \\
\hline 15 & 3.00 & 1.22 & 2.67 & 1.03 & 3.42 & 0.90 & 3.80 & 1.10 & 2.75 & 1.04 & 1.35 & 0.271 \\
\hline 16 & 3.23 & 1.54 & 3.67 & 0.82 & 3.08 & 1.51 & 2.80 & 2.05 & 4.00 & 1.07 & 0.78 & 0.544 \\
\hline 17 & 3.77 & 1.09 & 3.33 & 0.82 & 3.42 & 1.44 & 3.40 & 1.34 & 3.00 & 1.07 & 0.53 & 0.714 \\
\hline \multicolumn{13}{|c|}{ About the assignment } \\
\hline 18 & 3.92 & 1.44 & 3.33 & 1.51 & 4.58 & 0.51 & 4.00 & 1.92 & 3.63 & 1.69 & 1.23 & 0.313 \\
\hline
\end{tabular}

\section{Conclusions}

ESD is a critical enabler for sustainable development, helping individuals to better understand the impact of their lifestyle. This paper described an ESD activity proposed to make engineering students think about climate change, sustainability, and their responsibility to the environment as 
future engineers. To the best of authors' knowledge, this is the first activity of this type reported in the literature in the field of Robotic Engineering.

After completing the activity proposed, students were surveyed in order to determine their perception about sustainable development at four levels: Commitment, attitude, practices, and motivation. Responses were arranged in different groups for analyzing and comparing students' opinions depending on whether they did the assignment or not, depending on gender, and depending on the role they played in the working group. This study allowed us to answer the research questions proposed in the introduction of this work, as shown below.

Students demonstrated great commitment towards sustainable development (RQ1), with over 90\% of them agreeing on being concerned about wasteful consumption of natural resources and the need of conserving them for future generations. Students also strongly supported the role of their university in sustainability and social good. Around two-thirds also agreed on the importance of introducing such concepts in university courses and the Robotic Engineering curriculum program. Although commitment was high, respondents showed a poor attitude towards actively addressing sustainable development issues. This fact highlights the need to introduce more ESD activities that reinforce the awareness of the impact they can have as future engineers on the sustainability of the planet.

Regarding the comparison of students who did the assignment and those who did not (RQ2), the study showed no significant differences between these two groups. The limitations of the experimental setup (e.g., largely imbalanced groups) expose the need for further work to achieve better insights, such as performing pre-assignment and post-assignment questionnaires to students in order to verify whether the attitudes changed after carrying out the coursework.

The third research question (RQ3) addressed the possible differences between female and male students in terms of sustainability concerns. The analysis showed that female students presented significantly higher agreement on the need for their university to offer courses addressing the topic of sustainability. This group also achieved significantly higher agreement in two of the questions related to their involvement in campus sustainability: Their willingness to help to create a sustainable campus and the support for their university's initiatives to protect the environment. The key finding of this analysis was the significant difference in the last question of the survey, related to the motivational aspects of working on a topic such as climate change. Female students largely agreed on this aspect, confirming that topics related to social good, such as fighting climate change, can be an incentive and a way to attract and retain women in engineering.

The next research question (RQ4) sought to explore the differences between the answers given by the students depending on the role they played within their team. The results of this analysis did not clearly state that such differences existed, but there were hints to consider that a higher level of responsibility in the development of the activity proposed relates to a higher level of concern towards sustainability issues. An important lesson for future ESD activities is to try to evenly distribute the responsibility between all the members of the group to get the best of them.

Finally, the last analysis performed tried to identify if topics related to sustainability, such as climate change, can be motivational for students (RQ5). Overall, the results were positive, with almost two-thirds of the students agreeing on this point. The result was particularly noteworthy in the case of the female group, as mentioned above, since $95 \%$ of them agreed on considering sustainability issues as encouraging for their work.

In view of the results, future work should continue along this line, designing activities that not only introduce the concepts of ESD in Robotic Engineering degrees, but also motivate students in their coursework. An important task to carry out is to extend this type of activity to all the subjects of the degree so that it is not a one-off initiative in a subject, but it is integrated into all of them in a transversal way, providing a solid education in sustainability values to our future engineers. 
Author Contributions: Conceptualization, F.A.P. and D.T.; methodology, F.A.P. and D.T.; validation, F.A.P; formal analysis, D.T; investigation, F.A.P. and D.T.; resources, F.A.P.; data curation, D.T.; writing-original draft preparation, F.A.P. and D.T. All authors have read and agreed to the published version of the manuscript.

Funding: This research work was partially funded by the Spanish Government through project RTI2018-094653-B-C22.

Conflicts of Interest: The authors declare no conflict of interest.

\section{References}

1. Romero, S.; Aláez, M.; Amo, D.; Fonseca, D. Systematic Review of How Engineering Schools around the World Are Deploying the 2030 Agenda. Sustainability 2020, 12, 5035. [CrossRef]

2. Didham, R.J. Education for Sustainable Development and the SDGs: Learning to Act, Learning to Achieve, 2018. Available online: https://en.unesco.org/sites/default/files/gap_pn1_-_esd_and_the_sdgs_policy_ brief_6_page_version.pdf (accessed on 10 July 2020).

3. Byrne, E.; Desha, C.; Fitzpatrick, J.; Hargroves, K. Engineering education for sustainable development: A review of international progress. In Proceedings of the 3rd International Symposium for Engineering Education, 2010; Byrne, E., Ed.; University College Cork: Cork, Ireland, 2010; pp. 1-42.

4. Malheiro, B.; Silva, M.F.; Ferreira, P.D.; Guedes, P.B. Learning Engineering with EPS@ ISEP: Developing Projects for Smart Sustainable Cities. Int. J. Eng. Pedagog. (iJEP) 2019, 9, 33. [CrossRef]

5. Bugmann, G.; Siegel, M.; Burcin, R. A role for robotics in sustainable development? In Proceedings of the IEEE Africon '11, Livingston, Zambia, 13 September 2011; pp. 1-4.

6. Brinkhurst, M.; Rose, P.; abd Daniel Ackerman Josef, G.M. Achieving campus sustainability: Top-down, bottom-up, or neither? Int. J. Sustain. High. Educ. 2011, 12, 338-354. [CrossRef]

7. Richard, E.; Adams, J. College students' perceptions of campus sustainability. Int. J. Sustain. High. Educ. 2011, 12, 79-92. [CrossRef]

8. Vare, P.; Scott, W. Learning for a Change: Exploring the Relationship Between Education and Sustainable Development. J. Educ. Sustain. Dev. 2007, 1, 191-198. [CrossRef]

9. Adomßent, M.; Fischer, D.; Godemann, J.; Herzig, C.; Otte, I.; Rieckmann, M.; Timm, J. Emerging areas in research on higher education for sustainable development-Management education, sustainable consumption and perspectives from Central and Eastern Europe. J. Clean. Prod. 2014, 62, 1-7. [CrossRef]

10. Rieckmann, M. Future-oriented higher education: Which key competencies should be fostered through university teaching and learning? Futures 2012, 44, 127-135. [CrossRef]

11. Lozano, R.; Ceulemans, K.; Alonso-Almeida, M.; Huisingh, D.; Lozano, F.J.; Waas, T.; Lambrechts, W.; Lukman, R.; Hugé, J. A review of commitment and implementation of sustainable development in higher education: Results from a worldwide survey. J. Clean. Prod. 2015, 108, 1-18. [CrossRef]

12. Nomura, K.; Osamu, A. Higher education for sustainable development in Japan: Policy and progress. Int. J. Sustain. High. Educ. 2010, 11, 120-129. [CrossRef]

13. del Mar Alonso-Almeida, M.; Marimon, F.; Casani, F.; Rodriguez-Pomeda, J. Diffusion of sustainability reporting in universities: Current situation and future perspectives. J. Clean. Prod. 2015, 106, 144-154. [CrossRef]

14. Lozano-García, F.; Guillermo, G.; Orietta, P.; Mario, M.; Dora, E.H.; Donald, H. Capacity building: A course on sustainable development to educate the educators. Int. J. Sustain. High. Educ. 2008, 9, 257-281. [CrossRef]

15. Alshuwaikhat, H.M.; Abubakar, I. An integrated approach to achieving campus sustainability: Assessment of the current campus environmental management practices. J. Clean. Prod. 2008, 16, 1777-1785. [CrossRef]

16. Velazquez, L.; Munguia, N.; Platt, A. Fostering P2 practices in northwest Mexico through inter-university collaboration. J. Clean. Prod. 2000, 8, 433-437. [CrossRef]

17. Ferrer-Balas, D.; Bruno, J.; de Mingo, M.; Sans, R. Advances in education transformation towards sustainable development at the Technical University of Catalonia, Barcelona. Int. J. Sustain. High. Educ. 2004, 5, 251-266. [CrossRef]

18. Mesa, J.; Esparragoza, I.; Maury, H. Sustainability in engineering education: A literature review of case studies and projects. In Proceedings of the 15th LACCEI International Multi-Conference for Engineering, Education Caribbean Conference for Engineering and Technology, Latin American and Caribbean Consortium of Engineering Institutions 2017, Boca Raton, FL, USA, 19-21 July 2017. [CrossRef] 
19. Price, J.M.; Robinson, M. Developing Future Engineers: Case Study on the Incorporation of Sustainable Design in an Undergraduate Civil Engineering Curriculum. J. Water Resour. Plan. Manag. 2015, 141. [CrossRef]

20. Nazzal, D.; Zabinski, J.; Hugar, A.; Reinhart, D.; Karwowski, W.; Madani, K. Introduction of Sustainability Concepts into Industrial Engineering Education: A Modular Approach. Adv. Eng. Educ. 2015, 4, n4.

21. Exploring the Retention of Sustainable Design Principles in Engineering Practice Through Design Education, Volume 3: 17th International Conference on Advanced Vehicle Technologies; 12th International Conference on Design Education; 8th Frontiers in Biomedical Devices. In International Design Engineering Technical Conferences and Computers and Information in Engineering Conference; ASME: New York, NY, USA, 2015. [CrossRef]

22. Mitchell, C. Integrating Sustainability in Chemical Engineering Practice and Education: Concentricity and its Consequences. Process Saf. Environ. Prot. 2000, 78, 237-242. [CrossRef]

23. Rydhagen, B.; Dackman, C. Integration of sustainable development in sanitary engineering education in Sweden. Eur. J. Eng. Educ. 2011, 36, 87-95. [CrossRef]

24. Dempere, L. Understanding Sustainability Through Reverse Engineering. IEEE Technol. Soc. Mag. 2010, 29, 37-44. [CrossRef]

25. Benayas, J.; Marcén, C.; Alba, D.; Gutiérrez, J.M. Educación Para la Sostenibilidad en España. Reflexiones y Propuestas; Fundación Alternativas, REDS: Madrid, Spain, 2017. Available online: https:/ / www.miteco.gob.es/en/ceneam/grupos-de-trabajo-y-seminarios/redes_escolares/anexo1educacion-sostenibilidad-espana-reflexions-propuestas_tcm38-450990.pdf (accessed on 10 July 2020).

26. Sánchez-Carracedo, F.; Carbonell, B.S.; Francisco, M.M.P. Analysis of sustainability presence in Spanish higher education. Int. J. Sustain. High. Educ. 2020, 21, 393-412. [CrossRef]

27. International Commission on Education for the Twenty-first Century. Education for the Twenty-First Century: Issues and Prospects: Contributions to the Work of the International Commission on Education for the Twenty-First Century; Chaired by Jacques Delors; UNESCO Publishing: Paris, France, 1998.

28. Altbach, P.G.; Reisberg, L.; Rumbley, L.E. Trends in Global Higher Education: Tracking an Academic Revolution; Brill: Buckinghamshire, UK, 2019.

29. Bezanilla, M.J.; Fernández-Nogueira, D.; Poblete, M.; Galindo-Domínguez, H. Methodologies for teaching-learning critical thinking in higher education: The teacher's view. Think. Skills Creat. 2019, 33, 100584. [CrossRef]

30. Lima, R.M.; Andersson, P.H.; Saalman, E. Active Learning in Engineering Education: A (re)introduction. Eur. J. Eng. Educ. 2017, 42, 1-4. [CrossRef]

31. Boud, D. Problem-based learning in perspective. Probl.-Based Learn. Educ. Prof. 1985, 13, 13-18.

32. Lopes, D.C.; Gerolamo, M.C.; Del Prette, Z.A.P.; Musetti, M.A.; Del Prette, A. Social skills: A key factor for engineering students to develop interpersonal skills. Int. J. Eng. Educ. 2015, 31, 405-413.

33. Guerra, M.; Shealy, T. Teaching User-Centered Design for More Sustainable Infrastructure Through Role-Play and Experiential Learning. J. Prof. Issues Eng. Educ. Pract. 2018, 144, 05018016. [CrossRef]

34. Stouffer, W.B.; Russell, J.S.; Oliva, M.G. Making the strange familiar: Creativity and the future of engineering education. In Proceedings of the 2004 American Society for Engineering Education Annual Conference \& Exposition, Salt Lake City, UT, USA, 20-23 June 2004; Volume 9, pp. 1-9.

35. Davidson, C.N. Now You See It: How the Brain Science of Attention will Transform the Way We Live, Work, and Learn; Viking: New York, NY, USA, 2011.

36. Dewulf, S.; Baillie, C. CASE: Creativity in Art, Science and Engineering-How to Foster Creativity; Great Britain Department for Education and Employment: London, UK, 1999.

37. UNESCO. Education for Sustainable Development Goals: Learning Objectives; United Nations Educational, Scientific and Cultural Organization: Quito, Ecuador, 2017.

38. Lopez, D.; Sanchez, F.; Cruz, J.L.; Fernandez, A. Developing non-technical skills in a technical course. In Proceedings of the 37th Annual Frontiers In Education Conference, Milwaukee, WI, USA, 10-13 October 2007; pp. F3B-5-F3B-10.

39. Caetano, N.; López, D.; Cabré, J. Learning sustainability and social compromise skills: A new track is born. In Proceedings of the TEEM '15, Porto, Portugal, 7-9 October 2015. 
40. Arana-Pulido, V.; Cabrera-Almeida, F.; Perez-Mato, J.; Dorta-Naranjo, B.P.; Hernandez-Rodriguez, S.; Jimenez-Yguacel, E. Challenges of an Autonomous Wildfire Geolocation System Based on Synthetic Vision Technology. Sensors 2018, 18, 3631. [CrossRef] [PubMed]

41. Wang, J.; Yang, M.; Maresova, P. Sustainable Development at Higher Education in China: A Comparative Study of Students' Perception in Public and Private Universities. Sustainability 2020, 12, 2158. [CrossRef]

42. Khalil, D.; Ramzy, O.; Mostafa, R. Perception towards sustainable development concept: Egyptian students' perspective. Sustain. Account. Manag. Policy J. 2013, 4, 307-327. [CrossRef]

43. Association of University Leaders for a Sustainable Future (AULSF). Sustainability Assessment Questionnaire (SAQ) for Colleges and Universities; Association of University Leaders for a Sustainable Future (AULSF): Wayland, MA, USA, 2009.

44. The Gallup Organisation. Europeans' attitudes towards the issue of sustainable consumption and production: Analytical report. Flash EB Ser. 2009, 256, 1-18.

45. Hill, C.; Corbett, C.; Rose, A.S. Why so Few? Women in Science, Technology, Engineering, and Mathematics; ERIC: Washington, DC, USA, 2010.

46. Reinking, A.; Martin, B. The Gender Gap in STEM Fields: Theories, Movements, and Ideas to Engage Girls in STEM. J. New Approaches Educ. Res. 2018, 7, 148-153. [CrossRef]

47. Howell, D.C. Statistical Methods for Psychology; Cengage Learning: Belmont, CA, USA, 2009.

48. Tukey, J.W. Comparing Individual Means in the Analysis of Variance. Biometrics 1949, 5, 99-114. [CrossRef] [PubMed]

(C) 2020 by the authors. Licensee MDPI, Basel, Switzerland. This article is an open access article distributed under the terms and conditions of the Creative Commons Attribution (CC BY) license (http:// creativecommons.org/licenses/by/4.0/). 